\title{
Optimization Design of Large Corn Harvester Frame Based on Reliability Analysis
}

\author{
Lina Ma ${ }^{1, a}$, Yuefeng Dư ${ }^{1}$, Wen Zhou ${ }^{1}$, Zhenghe Song ${ }^{1}$, Shourong Liư ${ }^{1}$, \\ Zhongxiang Zhu ${ }^{1, b}$ \\ ${ }^{1}$ Beijing Key Laboratory of Optimization Design for Modern Agricultural Equipment, China \\ Agricultural University, Beijing, 100083, China \\ aemail: sunnylina@163.com, ${ }^{b^{*}}$ email: zhuzhonxiang@cau.edu.cn
}

\begin{abstract}
Keywords: Frame of Large Corn Harvester, Optimization Design, ANSYS, Reliability Analysis
\end{abstract}
\begin{abstract}
The main function of corn harvester frame is to bear loads from working parts, such as engine, cab, transmission, chopped header, husking machine. In this paper, three kinds of typical working conditions of corn harvester, namely, driving on uneven road at relatively high speed, braking and unloading, were researched. Then the most dangerous working condition was determined and used as a foundation to analyze the reliability of the frame. Based on reliability analysis results, it could be confirmed whether the structures of frame needed to be optimized. If needed, the sensitivity analysis results were applied as a support to optimize the structure parameters of frame. Based on above methods, the cross sections' parameters of longitudinal beams and cross beams were optimized to satisfy the requirement of the frame mechanical properties. As a result, the weight of the frame decreased by $19.6 \%$, which achieved the purpose of lightweight. It is concluded that this method is effective to reduce costs and improve efficiency in manufacturing processes. Furthermore, the method may be beneficial to improve the manufacturing level of harvesting machinery.
\end{abstract}

\section{Introduction}

Frame is a very significant part of large corn harvester, which is composed of cross beams and longitudinal beams and fitting seats. The frame is mainly used to fix engine, cab, cutting header, husking parts etc. When the harvester is working, the frame not only suffers the static loads from the weight of all components, but also bears the impact force and moment from uneven road.

As a new study, optimization design began in the early 1960s, providing a more reliable and efficient design method for designers and changing previous passive design into active design, hence raw materials can be saved and costs can be reduced. Moreover, the design cycle can be shortened and design efficiency and level can be improved. Meanwhile, the economic benefit, social benefit and competitiveness of enterprises are enhanced as well [1] [2]. Therefore, optimization design has become a necessary and essential part in producing processes of many industries products, such as aerospace and automobile manufacturing [3]. At present, when optimizing design the frame structures, the designers abroad not only considered the stress distribution and analyzed both the static and the dynamic strength \& stiffness, but also considered the noise and comfort under random excitation [4] [5] [6]. Yet in China, only several severe working conditions were used to analyze the static strength and stiffness of bus, truck, ATV and some other kinds of vehicle frames based on finite element analysis and the structures of their frames were optimized. However there were very few researches on optimization design of large corn harvester frame.

\section{Mechanical Analysis of Corn Harvester Frame under Three Typical Working Conditions}

\section{a) To Build the Finite Element Model}

One kind of corn harvester frame is chosen to be analyzed and its 3D model is shown in Figure 1. This kind of corn harvester frame is made of carbon structural steel Q235 with elastic modulus of 
$207 \mathrm{GPa}$, Poisson's ratio of 0.3 and density of $7.85 \times 10^{3} \mathrm{~kg} / \mathrm{m}^{3}$.

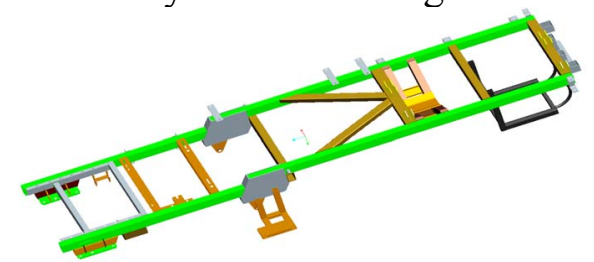

Fig.1. 3-D Model of one kind of corn harvester frame

After simplifying the 3D model without affecting the accurate of analysis results, the 3D model is meshed into finite element model by free mesh method whose element type is SOLID 185. The finite element model of frame is shown in Figure 2.

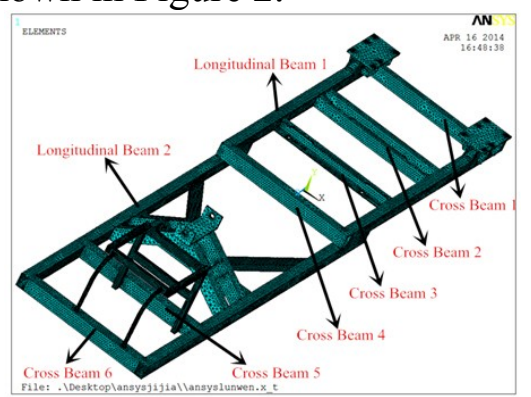

Fig.2. Finite element model of corn harvester frame

\section{b) Mechanical Analysis under Three Typical Working Conditions}

Frame of corn harvester is a main bearing component that is used to fix engine, cab, wheel axles, transmission parts, steering parts and chopped header, husking machine, etc. When carrying out finite element analysis of the frame, the weight of each component should be turned into a surface pressure applied to the corresponding position of the frame. $\mathrm{X}, \mathrm{Y}$ and $\mathrm{Z}$ directions of freedom are constrained at front axle, and only $\mathrm{X}$ and $\mathrm{Z}$ directions of freedom are constrained at rear axle.

(i) Driving on uneven road at relatively high speed

When the harvester driving on uneven road at relatively high speed, the load applied on the harvester frame is a product of the weight of all components and dynamic load coefficient. Dynamic load coefficient is determined by corn harvester driving speed and unevenness of road. The dynamic load coefficient of corn harvester is about 1.5-1.8 [10]. Under this condition, the Von-Mises stress and displacement vector sum distribution on the corn harvester frame are shown in Figure 3 and Figure 4, respectively.
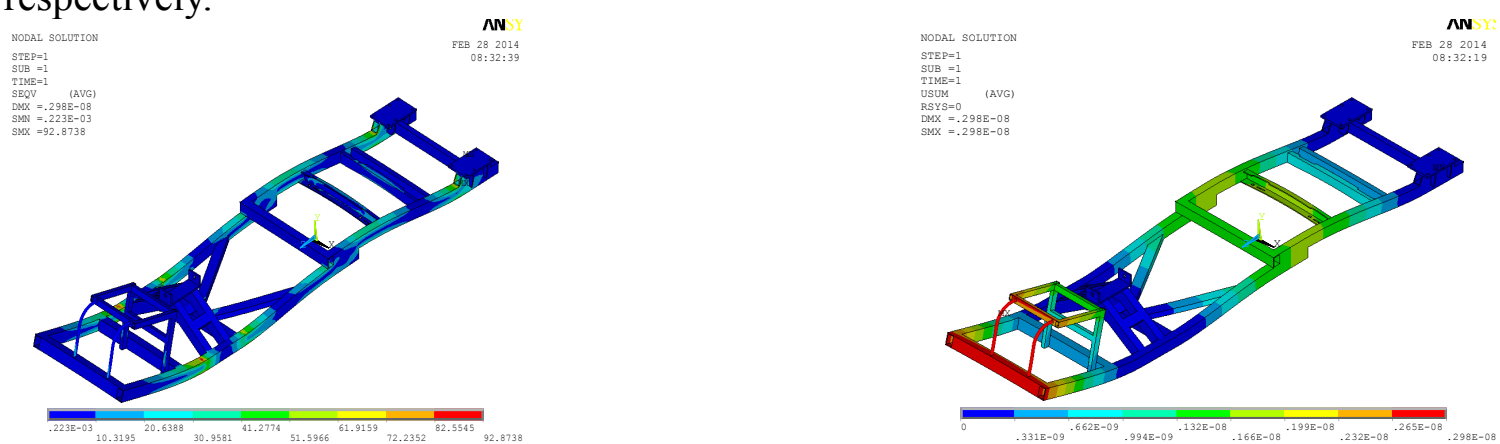

Fig.3. Von-Mises stress distribution under driving on uneven road at relatively high speed

Fig.4. Displacement vector sum distribution under driving on uneven road at relatively high speed

(ii) Braking

Braking condition is to simulate the strength and stiffness of corn harvester frame whose granary is full filled with corns when it brakes suddenly. There is a need to apply a braking deceleration of $2.94 \mathrm{~m} / \mathrm{s}^{2}$ in the forward direction. Under this condition, the Von-Mises stress and displacement vector sum distribution on the corn harvester frame are shown in Figure 5 and Figure 6, respectively. 

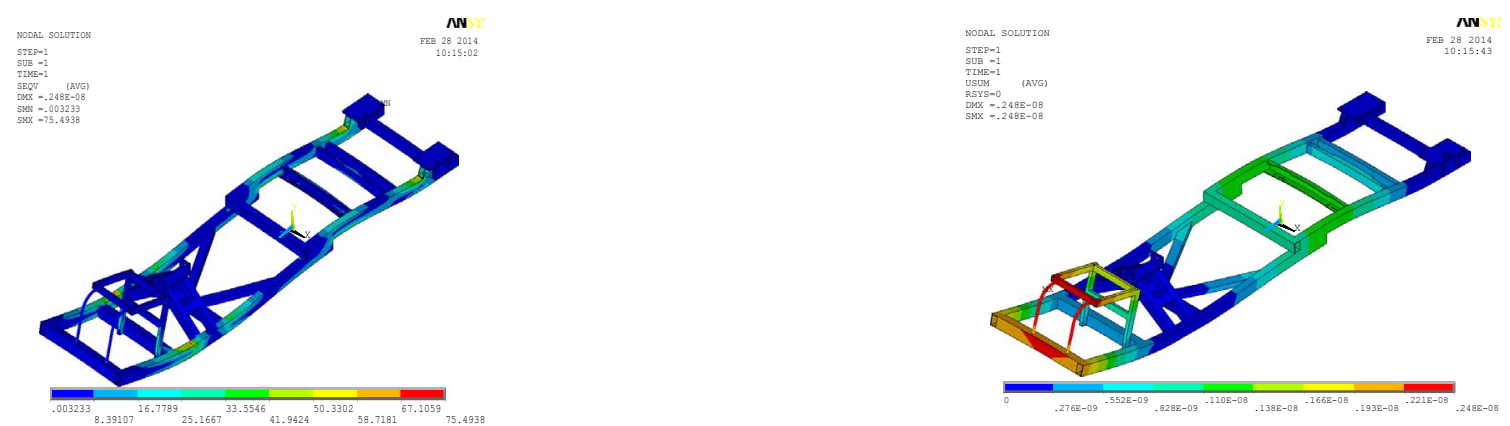

Fig.5. Von-Mises stress distribution under working condition of braking

Fig.6. Displacement vector sum distribution under working condition of braking

(iii) Unloading corns

Unloading corns condition is to simulate the strength and stiffness of the full loaded corn harvester frame when unloading its corns from granary. Under this condition, the Von-Mises stress and displacement vector sum distribution on the corn harvester frame are shown in Figure 7 and Figure 8, respectively.
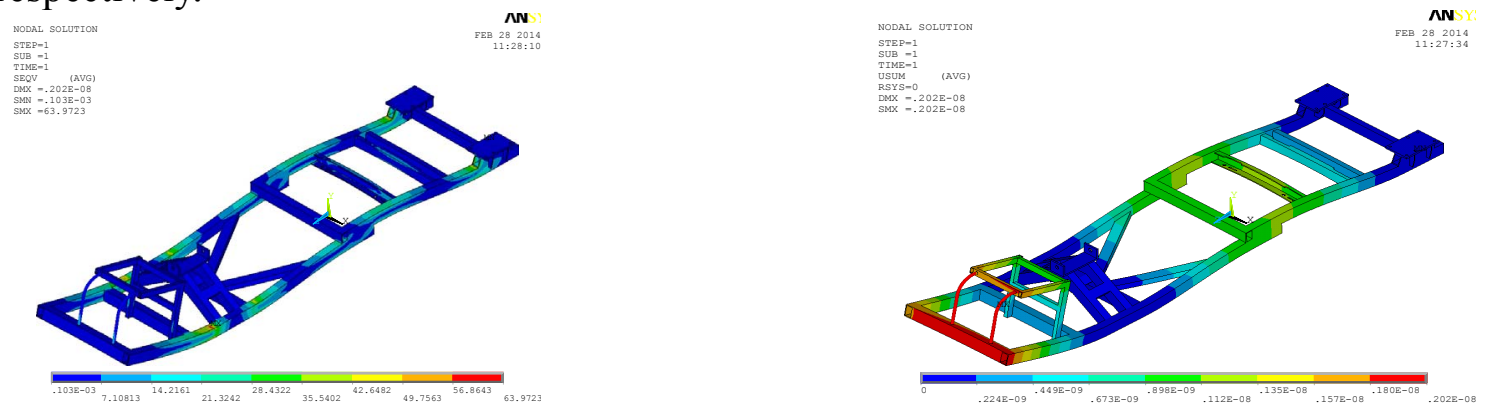

Fig.7. Von-Mises stress distribution under working condition of unloading corns

Fig.8. Displacement vector sum distribution under working condition of unloading

c) Comparisons of Maximum Stresses and Maximum Displacements under Each Working Condition

The maximum stress and maximum displacement on the dangerous section of each working condition are listed in Table 1.

Tab.1. Comparisons of maximum stresses and maximum displacements under each working condition

\begin{tabular}{ccc}
\hline Conditions & Stress/MPa & Deformation $/ \mathrm{mm}$ \\
\hline i & 92.9 & 2.41 \\
ii & 75.5 & 2.48 \\
iii & 63.9 & 2.02 \\
\hline
\end{tabular}

As shown in Tab.1, the maximum stress of the corn harvester frame happens in the working condition of driving on uneven road at relatively high speed. The point which maximum stress happens is located in connection between longitudinal beam and rear axle fitting seat.

Therefore, the working condition of driving on uneven road at relatively high speed is used as a foundation to do further reliability analysis and optimization.

\section{Optimization of Corn Harvester Frame}

\section{a) Optimization Design Process} 9.

Based on reliability analysis of corn harvester frame, the optimization process is shown in Figure 


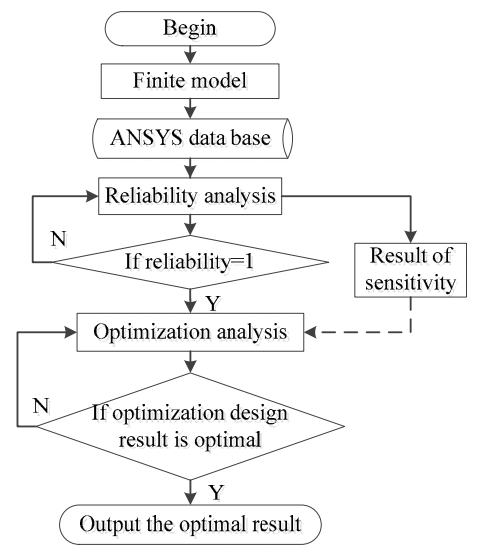

\section{b) Reliability Analysis}

Fig.9. Optimization Design Process of Corn Harvester Frame

It is necessary to make sure that the strength and stiffness of the corn harvester frame is sufficient because that is crucial to the safe use of the machine. The maximum stress should be less than the yield strength in the corn harvester working process. The maximum displacement should be no more than $0.5 \%$ of the length of corresponding beam [12]. Through the reliability analysis of corn harvester frame, if the probability is one, it is necessary to optimize the frame. If not, there is no need to do optimization. The random input variables of the corn harvester frame are listed in Table 2.

Tab.2. Random input variables used for reliability analysis

\begin{tabular}{|c|c|c|c|}
\hline Variables name & Distribution pattern & Parameter 1 & Parameter 2 \\
\hline Section width of longitudinal beam one $\left(B_{1}\right)$ & GAUS & 80 & 2.15 \\
\hline Section width of cross beam one $\left(B_{2}\right)$ & GAUS & 100 & 2.25 \\
\hline Section width of cross beam two $\left(B_{3}\right)$ & GAUS & 80 & 2.15 \\
\hline Section width of cross beam three $\left(B_{4}\right)$ & GAUS & 80 & 2.15 \\
\hline Section width of cross beam four $\left(B_{6}\right)$ & GAUS & 80 & 2.15 \\
\hline Section width of cross beam five $\left(B_{7}\right)$ & GAUS & 60 & 2.05 \\
\hline Section length of longitudinal beam one $\left(H_{1}\right)$ & GAUS & 120 & 3.64 \\
\hline Section length of cross beam three $\left(H_{4}\right)$ & GAUS & 120 & 3.64 \\
\hline Section length of longitudinal beam two $\left(H_{5}\right)$ & GAUS & 120 & 3.64 \\
\hline Section length of cross beam five $\left(H_{7}\right)$ & GAUS & 100 & 2.59 \\
\hline Section depth of longitudinal beam one $\left(T_{1}\right)$ & GAUS & 8 & 0.6 \\
\hline Section depth of cross beam one $\left(T_{2}\right)$ & GAUS & 8 & 0.6 \\
\hline Section depth of cross beam two $\left(T_{3}\right)$ & GAUS & 8 & 0.6 \\
\hline Section depth of cross beam three $\left(T_{4}\right)$ & GAUS & 8 & 0.6 \\
\hline Section depth of longitudinal beam two $\left(T_{5}\right)$ & GAUS & 8 & 0.6 \\
\hline Section depth of cross beam four $\left(T_{6}\right)$ & GAUS & 8 & 0.6 \\
\hline Section depth of cross beam five $\left(T_{7}\right)$ & GAUS & 8 & 0.6 \\
\hline Section depth of cross beam six $\left(T_{8}\right)$ & GAUS & 8 & 0.6 \\
\hline Pasion ratio (PSB) & GAUS & 0.28 & 0.1 \\
\hline Load of granary $\left(F_{1}\right)$ & LOG1 & 20500 & 564 \\
\hline Load of peeling machine $\left(F_{2}\right)$ & LOG1 & 18190 & 423 \\
\hline Load of engine $\left(F_{3}\right)$ & LOG1 & 8500 & 46 \\
\hline Load of cab $\left(F_{4}\right)$ & LOG1 & 7730 & 33 \\
\hline
\end{tabular}

In the reliability analyzing process, the maximum Von-Mises stress denoted by VONSTRESSMAX and maximum displacement denoted by DEFLM are set as the random output variables, choosing Monte Carlo method to analysis and setting 800 times to simulate. The analysis results are shown in Figure 10 and Figure 11. 

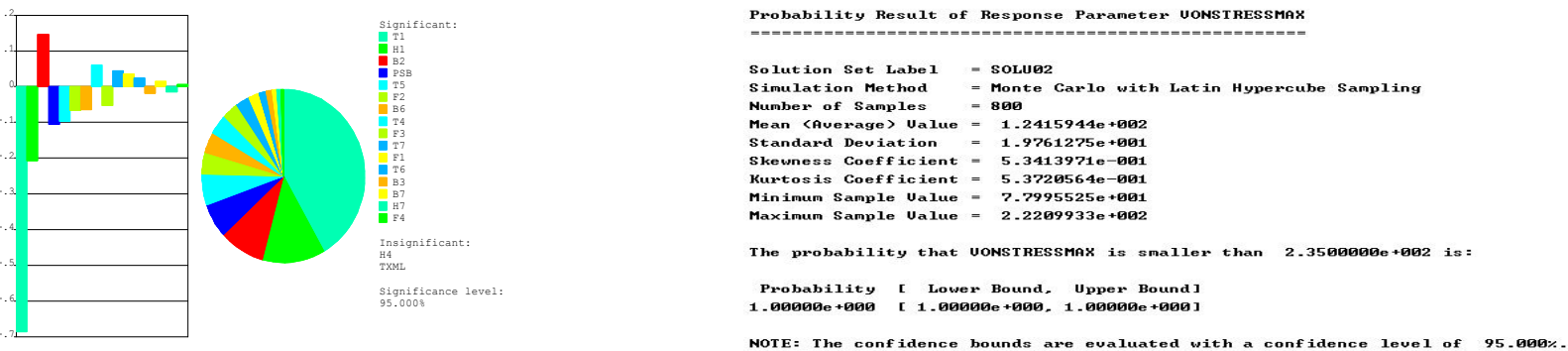

Fig.10. Result of sensitivity analysis

Fig.11. Probability result of output variable VONSTRESSMAX

In Figure 10, the result indicates the impact of input variables on the output variable. In Figure 11 , the maximum value of output variable VONSTRESSMAX is $222.099 \mathrm{MPa}$, meanwhile the minimum value of output variable is $77.996 \mathrm{MPa}$. The probability is 1 when the confidence bounds are evaluated with a confidence level of $95 \%$, so that it is possible to optimize the corn harvester frame.

\section{c) Corn Harvester Frame Optimization}

(i) Mathematical modeling

Under the premise of satisfying the requirement of corn harvester frame mechanical properties, optimization of corn harvester frame structures and parameters aims to achieve the goal of lightweight of the frame. Therefore, the total volume of the frame, $\min F(x)$, is set as objective function, which is expressed by Equation (1).

$\min F(x)=V_{1}(x)+V_{2}(x)+V_{3}(x)$

Where, $V_{1}(x)$ is total volume of cross beams, $V_{2}(x)$ is total volume of longitudinal beams, $V_{3}(x)$ is the volume of rest parts.

The optimal design variables are section parameters of cross beams and longitudinal beams. As a result of sensitivity analysis shown in Figure10, the variables which have greater impact on output variables are chosen as optimization design variables. The design variable $\mathrm{X}$ is described by Equation (2).

$$
X=\left\{B_{2}, B_{3}, B_{6}, B_{7}, H_{1}, T_{1}, T_{4}, T_{5}, T_{6}, T_{7}\right\}
$$

The yield strength and admissible stiffness are defined as state variables. The main material of corn harvester frame is Q235. Considering the safety coefficient of the frame strength, the constraint function of the frame strength can be described by Equation (3).

$$
U_{1}=\sigma_{\max }-\frac{\left[\sigma_{s}\right]}{K} \leq 0
$$

Where, $\sigma_{\max }$ is maximum stress, $\left[\sigma_{\mathrm{s}}\right]$ is yield strength of frame material whose general value is $235 \mathrm{MPa}, K$ is safety coefficient due to stress concentration and machined surface quality and other influence factors whose general value is between 1.3 and 1.8 .

Stiffness constraint of the frame is to restrict its maximum deformation and the equation can be expressed by Equation (4).

$$
U_{2}=\delta_{\max }-\left[\delta_{s}\right] \leq 0
$$

Where, $\delta_{\max }$ is the maximum deformation of the frame, $\left[\delta_{s}\right]$ is the admissible maximum deformation.

Given all that, the optimization design mathematical model of the corn harvester frame can be defined as Equation (5).

$$
\left\{\begin{array}{l}
\min F(x)=V_{1}(x)+V_{2}(x)+V_{3}(x) \\
x=\left\{B_{2}, B_{3}, B_{6}, B_{7}, H_{1}, T_{1}, T_{4}, T_{5}, T_{6}, T_{7}\right\} \\
U_{1}=\sigma_{\max }-\frac{\left[\sigma_{s}\right]}{K} \leq 0 \\
U_{2}=\delta_{\text {max }}-\left[\delta_{s}\right] \leq 0
\end{array}\right.
$$

(ii) Optimal results 
First-Order method is adopted and maximum iteration times are set to 70, then the result that the total volume of the frame is changing with iteration times is obtained, as shown in Figure 12. Meanwhile, the changing process of maximum stresses with iteration times is shown in Figure 13.
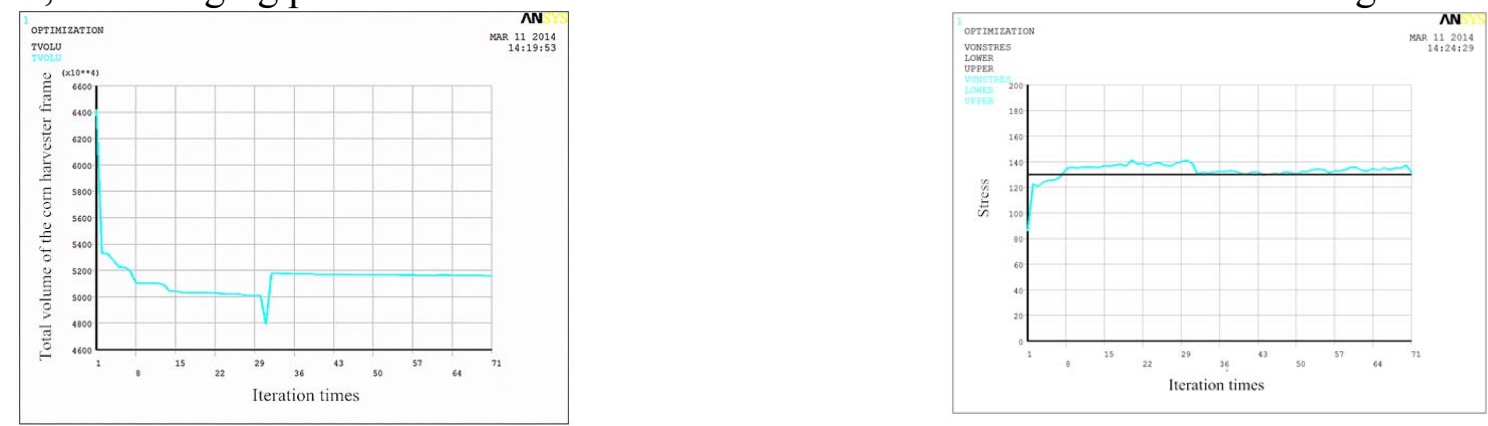

Fig.12. Change curve of the frame total volume with iteration times

Fig.13. Change curve of the maximum stresses on the frame with iteration times

After 70 iterations, comparisons of the optimization result of each variable with its obvious value are shown in Table 3.

Tab.3. Comparisons of variables before and after optimization

\begin{tabular}{cccc}
\hline Optimization variables & Initial value & Optimization results & Rate of change \\
\hline Total volume & $0.64 \mathrm{E} 8$ & $0.52 \mathrm{E} 8$ & $-19.6 \%$ \\
The maximum deformation & 3.17 & 6.90 & $+54 \%$ \\
The maximum stress & 86.09 & 131.22 & $+34.4 \%$ \\
$B_{2}$ & 100.00 & 99.16 & $-0.84 \%$ \\
$B_{3}$ & 80.00 & 78.02 & $-2.48 \%$ \\
$B_{6}$ & 80.00 & 79.30 & $-0.88 \%$ \\
$B_{7}$ & 60.00 & 59.00 & $-1.48 \%$ \\
$H_{1}$ & 120.00 & 95.83 & $-20.1 \%$ \\
$T_{1}$ & 8.00 & 5.71 & $-28.6 \%$ \\
$T_{4}$ & 8.00 & 7.48 & $-6.5 \%$ \\
$T_{5}$ & 8.00 & 5.79 & $-27.6 \%$ \\
$T_{6}$ & 8.00 & 7.36 & $-8.04 \%$ \\
$T_{7}$ & 8.00 & 7.34 & $-8.27 \%$ \\
\hline
\end{tabular}

It can be seen from Table 3 that although the maximum displacement increases to $6.9 \mathrm{~mm}$ and the maximum stress increases to $131.22 \mathrm{MPa}$, they are both within allowable ranges. There are some changes in the section parameters of both cross beams and longitudinal beams, among which the section depth of longitudinal beam has the largest reductions of up to $28.6 \%$, agreeing with the result of sensitivity analysis got from reliability analysis. Hence the volume of corn harvester frame is reduced by $19.6 \%$, so is the weight, achieving the purpose of lightweight of the frame.

\section{Conclusion}

This paper analyzed the mechanical properties of corn harvester frame under three typical working conditions consisting of driving on uneven road at relatively high speed, suddenly braking and unloading corns. And then the most dangerous working condition was selected and used to analyze the reliability of the frame.

Based on reliability analysis, structure parameters which had great influence on the mechanical properties of the corn harvester frame were confirmed, accordingly the structures of the corn harvester frame were optimized, improving the sectional dimensions of cross beams and longitudinal beams. Therefore the weight of the corn harvester frame was reduced by $19.6 \%$, achieving the purpose of lightweight of the frame.

\section{Acknowledgement}

The research work was supported by the "12th Five-Year" National Sci-Tech Support Plan 
Projects (2012BAF07B01).

\section{References}

[1] Bai Xinli. Structure optimization design [M]. Henan: Yellow River Water Conservancy Press, 2008.

[2] Guo Zhongze, Zhang Weihong, Chen Yuze. An overview on the topological optimization design of structures [J]. Journal of Machine Design, 2007, 24(8): 1-5.

[3] Kim. H. S., Huh H. Vehicle structural collapse analysis using a finite element limits method [J]. Korea Advanced Inst of Science and Technology, 1999, (21): 436-449.

[4] Hadad H, Ramezani A. Finite element model updating of a vehicle chassis frame [J]. Proceedings of the 2004 International Conference on Noise and Vibration Engineering, 2004, 1817-1831.

[5] Karsten Kolk, Gunther Kuhn. The advanced simulation of fatigue crack growth in complex 3D structures [J]. Arch Appl Mech, 2006, 76: 699-709.

[6] Xue Dawei, Zhao Yuyang. Finite element static analysis of passenger car frame [J]. Journal of Harbin Institute of Technology, 2006, 38(7): 1075-1078.

[7] Zhang Lixiang, Liu Shourong, Mao Enrong, Xie Bin, Li Fuqiang. Reliability analysis of agricultural machinery chassis drive axle housing based on ANSYS [J]. Transactions of the CSAE, 2013, 29(2): 37-44.

[8] Fenga Zhengkun, Champliauda Henri, Sabourinb Michel, Morina Sebastien. Optimal blank design based on finite element method for blades of large Francis turbines [J]. Simulation Modelling Practice and Theory, 2013, 36:11-21.

[9] Wanga Jia, Katafygiotisb L.S., Reliability-based optimal design of linear structures subjected to stochastic excitations [J]. Structural Safety, 2014, 47(3): 29-38.

[10] Wang Zhi-min, Zhang Tu-qiao, Wu Xiao-gang. Equivalent vehicle dynamic load coefficient on rough pavement [J]. Journal of Zhejiang University: Engineering Science, 2007, 41(6): 1007-1011.

[11] Chen Jian, Xu Chenxia. Optimization design and reliability analysis of engine mount system [J]. Automotive Engineering, 2009, 31(3): 234-238.

[12] Zhang Hongwei, Zhang Yidu, Wang Xiping, Zhou Shenjie. Optimization design of an agricultural vehicle frame based on ANSYS parametric modeling [J]. Transactions of the Chinese Society for Agricultural Machinery, 2007, 38(3): 35-38.

[13] Zhao Han, Qian Demeng. Research on lightweight design of automobile structure based on ANSYS [J]. Transactions of the Chinese Society of Agricultural Machinery, 2005, 36(6): 12-15. 